\title{
Assessment of the Utilization Pattern and Related Knowledge about Topical Nasal Decongestants among the Users
}

\author{
Valli Rajasekaran, ${ }^{1}$ Puja Ghosh ${ }^{1}$
}

\begin{abstract}
Introduction
Nasal decongestants are one of the drugs commonly prescribed by otorhinolaryngologists in their day to day practice. The excessive or inappropriate use of nasal decongestant due to rapid symptomatic reliefleads to drug misuse or abuse. Inadequate knowledge about the drug usage leads to inappropriate drug usage.

Materials and Methods

A cross sectional study was done among 90 patients who were using topical nasal decongestants. A pre tested, pre validated questionnaire was used to assess the patient's knowledge, the utilization pattern and the attitude towards the drug usage.

$\underline{\text { Results }}$

The mean age of presentation in our study was 38.4 years. Only $14.4 \%$ of the people knew the appropriate duration of drug usage. Only 33.3\% knew about the probable side effects of prolonged drug usage. There was a significant correlation between knowledge and utilisation pattern of topical nasal decongestants usage and the literacy level. Though most of the people (46.7\%) started using the drug after being prescribed by a doctor, only $14.3 \%$ among them strictly adhered to doctor's instructions. $82 \%$ of the users were not worried about the prolonged usage as $73.3 \%$ believed that prolonged use may or will surely improve their symptoms. Though $66.7 \%$ users wanted to stop prolonged usage of the drug, $76.9 \%$ had varying difficulties in stopping the drug. Conclusion

The knowledge and the utilization pattern regarding the drug usage were very low. The same was found to be better with increase in literacy level. Health professionals should play a major role in establishing a rational drug usage.

$\underline{\text { Kevwords }}$

Nasal Decongestants; Self Medication; Health Literacy; Cross-Sectional Studies; Surveys and Questionnaires
\end{abstract}

ABSTRACT

$\mathrm{T}$ opicalnasaldecongestantscanbesympathomimetic amines or imidazole derivatives which cause vasoconstriction thereby reducing congestion and edema of nasal mucosa. These are commonly used to treat nasal obstruction in rhinosinusitis, allergic rhinosinusitis, nasal polyposis and following nasal surgeries ${ }^{1}$ and are one of the most commonly prescribed drugs in ENT practice.

Topical nasal decongestants act much faster when compared to oral nasal decongestants which take about 15-30 minutes. This becomes the reason why people tend to abuse this drug. The prevalence of intranasal decongestant overuse was $49 \%$. $^{2}$ Topical nasal decongestants are available over the counter without clinician's prescription in some countries like India ${ }^{2}$ and hence are perceived as harmless drug by the users.
Self-medication is very common even among educated population. ${ }^{3,4}$ The practise of self medication is around $11.9 \%$ in urban Puducherry, South India. ${ }^{5}$

Among the numerous local and systemic complications associated with prolonged use of topical nasal decongestants, Rhinitis medicamentosa (RM) is a drug induced non allergic rhinitis. ${ }^{6}$ The incidence of $\mathrm{RM}$ has been documented in various studies between $1-9 \%{ }^{7,8}$ There is a lot of difference in opinion among various authors about the duration of use of topical nasal

1 - Department of ENT, Shri Sathya Sai Medical College and Research Institute, Kancheepuram, Tamil Nadu

\section{Corresponding author:}

Dr Puja Ghosh

email: drpujaghosh@gmail.com 
decongestant ranging from about 3 days to 2 months. However, the risk of Rhinitis Medicamentosa is more when topical nasal decongestants are used for more than 10 days. $^{9}$

Depending on the knowledge and attitude about the dosage and side effects of topical nasal decongestants, the utilization pattern of the same varies among its users. ${ }^{2}$ Very few studies are available regarding the knowledge and usage of topical nasal decongestants among its users. This study will help us in identifying the knowledge about the appropriate usage and the utilization pattern of topical nasal decongestants.

\section{Materials and Methods}

A cross sectional study was done in the ENT department for a period of 6 months from June 2017 to November 2017. The institutional ethical committee clearance was obtained. 90 patients above 18 years of age who visited our outpatient department (OPD) and were using topical nasal decongestants were included in our study. People using steroid sprays were excluded. Patients who were willing to participate in the study were enrolled in the study after obtaining an informed written consent. Patients were interviewed using pre tested and pre validated questionnaire (in the regional language Tamil) which contained details about sociodemographic factors, knowledge, attitude and practice about the use of topical nasal decongestants and their side effects. The data was collected and statistical analysis was done using SPSS software version 23. The data on knowledge, attitude and the practice regarding the use of topical nasal decongestants were analysed using descriptive statistics. The correlation between the knowledge and the utilization pattern with the literacy level were derived using chi square test.

\section{Results}

The study was done among 90 patients who were using topical nasal decongestants. The age of the patients in the study was ranging from 22-62 years. The mean age of presentation is 38.4. Most of the patients were males $(60 \%)$ and the remaining were females $(40 \%)$.

Most of the people who were using topical nasal decongestants had finished intermediate or post high school diploma (30\%). Two of the patients who were abusing the drugs were medicos (professional) and only few $(6.7 \%)$ were illiterates (according to Revised Kuppuswamy's classification). ${ }^{10}$

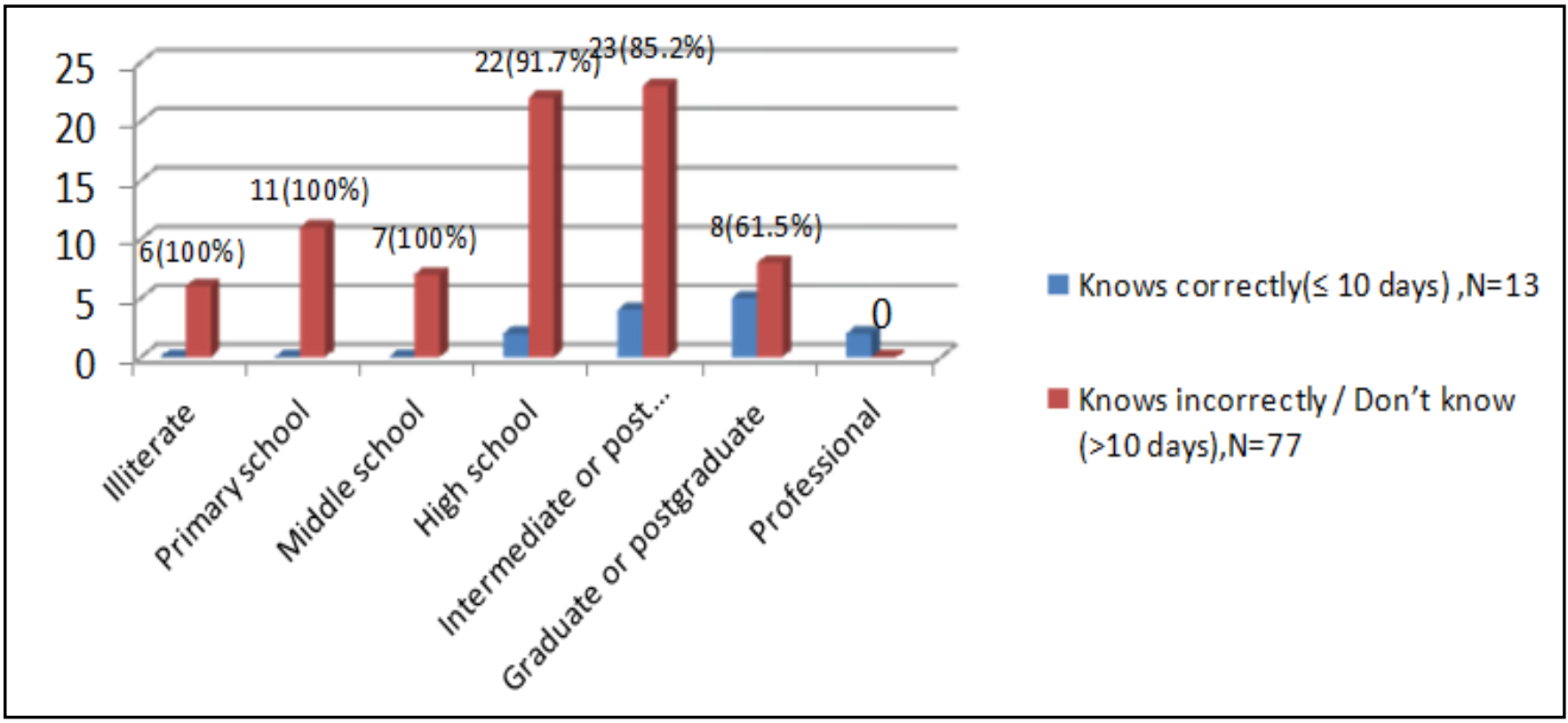

Fig. 1. Relation between knowledge about the appropriate duration of use of topical nasal decongestant and their education status 


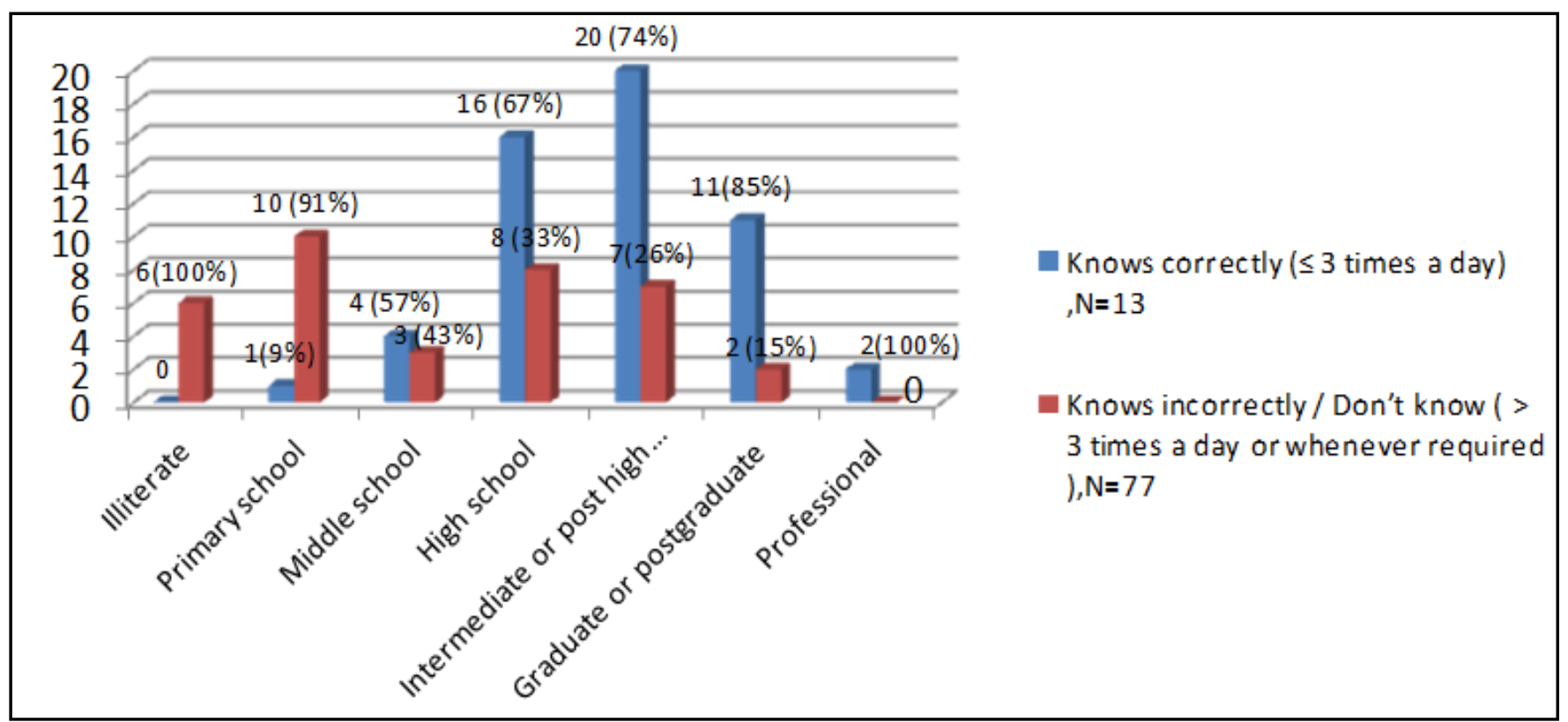

Fig. 2. Relation between knowledge about the appropriate frequency of use of topical nasal decongestant and their education status

The most common complaint for which the drug was prescribed was for nasal obstruction (83.3\%). The second most common reason was following nasal surgeries (septal surgeries / FESS / turbinoplasty) which were about $30 \%$.

Most of the patients $(60 \%)$ were not aware of the exact duration of the drug usage. Among the people who knew about the duration of usage, only a few (14.4\%) were aware of the exact dosage. The exact duration of drug usage was taken as less than 10 days. People who were using the drug for less than 10 days were considered as "knows correctly" and was compared with the literacy level. All the professionals were aware of the duration of the drug usage (Fig. 1).There was statistically significant association between the level of literacy and the knowledge about duration of drug usage $(\mathrm{p}=0.001)$

Most of them $(60 \%)$ were aware of the frequency of usage. People who know that the drops can be used for $\leq 3$ times a day were considered as "knows correctly". Their knowledge about the frequency of drug usage was compared with the literacy level (Fig. 2). There was statistically significant association between the level of literacy and the knowledge about the frequency of drug usage $(\mathrm{p}=0.000)$.
The knowledge about the side effects of topical nasal decongestants was very poor. Only $33.3 \%$ of the users were aware about the side effects. The most common side effects that the people were aware being nasal obstruction and burning sensation of nose, followed by hyposmia, epistaxsis and headache.

Most people started using the drug after being prescribed by the treating doctor(46.7\%).(Fig. 3).Among the people who were prescribed by the doctor, $71.4 \%$ were instructed about the appropriate dosage and only $42.8 \%$ were clearly explained about the side effects of decongestant use. Chemists and advertisements in media had a significant role in initiating the use of topical nasal decongestants. Only $33.3 \%$ of the people who started using after being dispensed by chemist were informed about the dosage and none of them were explained about the side effects. Other sources of information were from peers, friends and family members.

Only $13.3 \%$ of the people were using the drops for less than 10 days. $40 \%$ of the patients were using the drops for more than 3 months. The duration of use was ranging maximum up to 3 years. Among the people who were using the drug for more than 10 days, $50 \%$ of them were using the drug only if they were symptomatic (more than 4 times a day). With increase in literacy level 


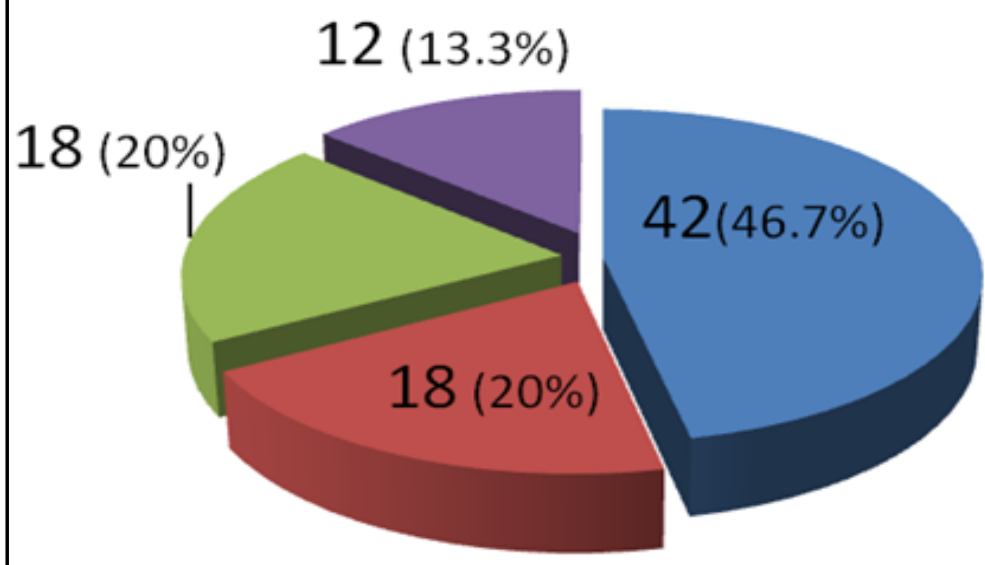

Doctor's prescription

dispensed by chemist

Media advertisements

\section{others}

Fig. 3. How did you start using the drug?

the utilisation pattern was found to be better (Fig. 4). There was statistically significant association between the level of literacy and the proper utilisation pattern of the drug $(\mathrm{p}=0.033)$.

Only $14.3 \%$ of the patients were following the doctor's instructions all the time. Most of them (42.8\%) were very rarely following the instructions (Fig. 5).
The attitude of the people regarding the use of topical nasal decongestants is analysed as shown below. (Table I)

\section{Discussion}

This study was conducted in our medical college among

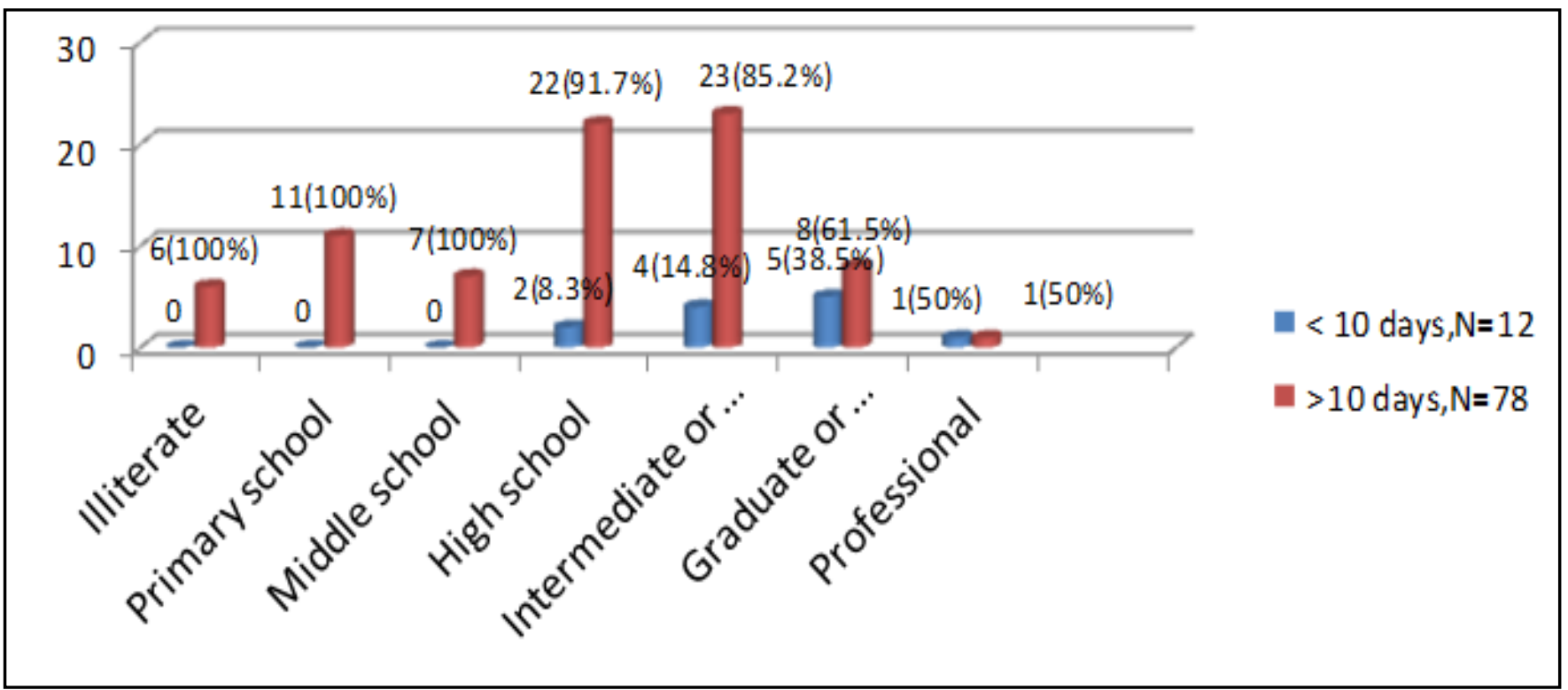

Fig. 4. Relation between utilization pattern of topical nasal decongestant and their educational status 


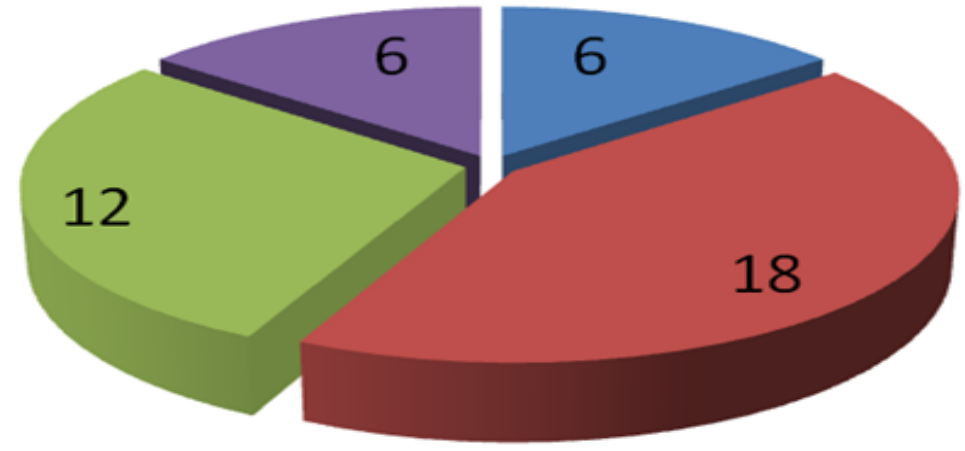

Not at all

Very rarely

Most of the time

All the time

\section{Fig.5. Distribution of study population based on their adherence to treating doctor's instruction}

90 patients using topical nasal decongestants. The mean age of presentation was 38.4 years. Most of them were males.

The findings in our study shows that only $14.4 \%$ people were aware of the appropriate duration of use of topical nasal decongestants ( $<10$ days). Similar findings have been documented in a study by Gill et al., where only $30 \%$ of the participants knew the recommended duration of use of topical nasal decongestants. ${ }^{11} \mathrm{We}$ observed that the literacy level has significant impact on the knowledge about the duration and frequency of usage of topical nasal decongestants. Higher the educational qualification better was their knowledge about the drug. It would be safe, if the people, who are using any drug, have sufficient knowledge about the drug's dose, time of intake, side-effect on over dose. ${ }^{12}$

Only $33.3 \%$ of the people were aware about the side effects of prolonged use of topical nasal decongestants. The finding in our study is supported by a similar study, where $32.9 \%$ were aware about the side effects. ${ }^{13}$

In our study, for most of the people the drug was prescribed by a doctor (46.7\%). Among them $71.4 \%$ were offered guidance regarding the drug usage, $42.8 \%$ were explained about the side effects. In their study Gill et al. ${ }^{11}$, Lenz et al. ${ }^{13}$ and Zareen et al. ${ }^{14}$ showed a similar number of people being prescribed and explained about the dosage and side effects by the physician. The findings in these studies are similar to the findings in our study. Health professionals have a potential role in preventing risks of self-medication. It is the duty of the consultant to explain about the prescribed drug, to provide therapeutic advice and to educate the patient. ${ }^{12}$

In our study, the source of information from advertisements in media was $20 \%$. This could probably explain the role of media in influencing the drug usage in our country. Likewise advertisements have played a major role in initiating self medications of different drugs in various parts of India ${ }^{15,16}$ and other countries around the world (Pakistan ${ }^{17}$, Poland ${ }^{18}$ ). About 53.3\% of the study population started using the drug without doctor's advice. Similar results were found in a study done in Brazil by Lenz et al, where 53\% population were using topical nasal decongestant without a doctor's prescription. ${ }^{13}$ In a study done in Jordan, systemic nasal decongestants are the highest purchased drugs $(61.8 \%)$ without a doctor's prescription ${ }^{17}$ but there is not much similar data available regarding topical nasal decongestants. In a study done by Selvaraj et al. amongst a population residing in urban Puducherry, $66.6 \%$ believed the concept of self-medication is harmless. ${ }^{5}$ Similar results been obtained in a study done 
Table I: Distribution of study population based on attitude towards usage of topical nasal decongestants

\begin{tabular}{|c|c|c|c|c|}
\hline QUESTION & \multicolumn{4}{|c|}{ OPTIONS } \\
\hline \multirow{2}{*}{$\begin{array}{l}\text { 1. Do you think prolonged of topical nasal } \\
\text { decongestants will improve your present condition? } \\
(\mathrm{N}=90)\end{array}$} & $\begin{array}{l}\text { Will surely } \\
\text { improve }\end{array}$ & May improve & Not sure & $\begin{array}{c}\text { Will } \\
\text { worsen }\end{array}$ \\
\hline & $19(21.1 \%)$ & $47(52.2 \%)$ & $22(24.5 \%)$ & $02(2.2 \%)$ \\
\hline \multirow{2}{*}{$\begin{array}{l}\text { 2.Did you worry about our prolonged use of topical } \\
\text { nasal decongestants } ?(N=78)\end{array}$} & Not at all & A little & Quite a lot & $\begin{array}{l}\text { A great } \\
\text { deal }\end{array}$ \\
\hline & $22(28.2 \%)$ & $42(53.8 \%)$ & $\mathbf{0}$ & $14(18 \%)$ \\
\hline \multirow{2}{*}{$\begin{array}{l}\text { 3.Did you wish you could stop using the nasal } \\
\text { drops? }(\mathrm{N}=78)\end{array}$} & Never & Sometimes & Often & Always \\
\hline & $26(33.3 \%)$ & $36(46.2 \%)$ & $10(12.8 \%)$ & $6(7.7 \%)$ \\
\hline \multirow{2}{*}{$\begin{array}{l}\text { 4. How difficult would you find to stop using the } \\
\text { topical nasal decongestants? }(\mathrm{N}=78)\end{array}$} & Not difficult & $\begin{array}{l}\text { Quite } \\
\text { difficult }\end{array}$ & $\begin{array}{l}\text { Very } \\
\text { difficult }\end{array}$ & Impossible \\
\hline & $18(23.1 \%)$ & $49(62.8 \%)$ & $11(14.1 \%)$ & $\mathbf{0}$ \\
\hline
\end{tabular}

by Ahmad et al. amongst rural and urban north Indian population shows almost $60 \%$ of respondents believed that consuming non-prescriptions is safe..$^{20}$

Our study showed that only $13.3 \%$ of people were using the drops for less than 10 days. However in a study by Lenz et al. showed $64.7 \%$ of the users were using the drops for less than 15 days. ${ }^{13}$ This could be because this study was done among the students of health sciences. In our study $20 \%$ of the people have used the drug for more than a year. Similar results have been documented in the study by Lenz et al. $(12.7 \%) .^{13}$ In a study done by Mehuys et al. $49 \%$ of the people were using the drug for at least a year. ${ }^{2}$ This could be because, the study was done among people visiting pharmacy for self medication whereas in our study people who visited hospital OPD alone were included.

The education level of the patient had a positive effect on the utilization pattern of the drug in our study. Similar findings have been documented in study by Gill et al. among students of health sciences, where the utilization pattern was good. ${ }^{11}$
Only $2.2 \%$ of patients knew that continued use of decongestant will worsen the symptoms. Most of them $(73.3 \%)$ believed that there will /may be some improvement. This could be because of poor knowledge on appropriate dosage and side effects among the drug users

Most of the patients (72\%) were worried about prolonged use, but still they had continued the drug usage. This could be because of rapid symptom relief provided by the drug. Our result is supported by another study done by Ahmad et al., which shows $75 \%$ of the patients were worried that prolonged usage of a drug may cause side effects and dependency. ${ }^{20}$ In our study, one third of the patients had never thought of discontinuing the drug usage. This clearly highlights the ignorance about the adverse effects and dependence on the drug. All the patients felt varying degree of difficulty in discontinuing the drug usage.

The results of our study shows that we need to go a long way as far as creating awareness about usage of topical nasal decongestants. As these drugs are commonly 
prescribed by physicians, paediatricians, general practitioners in addition to otorhinolaryngologist, these treating doctors should be motivated to educate the patient. In fact in rural and suburban regions even the chemists have to be trained to educate and convince the patients not to abuse or misuse the drug. Media should also emphasis on the usage of the drug only with consultation by a doctor.

\section{Conclusion}

The knowledge about appropriate duration, frequency of use and side effects of topical nasal decongestant was very low. The knowledge and utilisation pattern of topical nasal decongestants was better with increase in literacy level .Most people have self medicated the drug without consulting a doctor. The ease of availability of the drug has to be regulated. Most of the people were not worried about prolonged use as they believed that continued use will improve their symptoms. People had varying degrees of difficulties in stopping the drug use. Improved knowledge and understanding about the topical nasal decongestants may result in rationale use. Health professionals play a vital role in educating the patient.

\section{References}

1. Zaffani E, Rufca GF, Kamimura A, Maniglia JV, Fernades AM. Epidemiological profile of patients using topical nasal decongestants from the otorhinolaryngology clinic of a university hospital. Arq. Ciênc. Saúde 2007; 14:95-8

2. Mehuys E, Gevaert P, Brusselle G, Van Hees T, Adriaens E, Christiaens $T$ et al. Self-medication in persistent rhinitis: overuse of decongestants in half of the patients. The Journal of Allergy and Clinical Immunology: In Practice 2014; 2(3):313-9

3. Shveta S, Jagmohan S. A study of self-medication pattern in Punjab. Indian J Pharm Pract. 2011; 4:43-8

4. Joshi MC, Shalini, Agarwal S. A questionnaire based study of self-medication practices among young population. Res. J. Pharm. Biol. Chem. Sci. 2011; 2:761-6

5. Selvaraj K, Kumar SG, Ramalingam A. Prevalence of selfmedication practices and its associated factors in Urban Puducherry, India. Perspectives in Clinical Research 2014; $5(1): 32$
6. Doshi J. Rhinitis medicamentosa: what an otolaryngologist needs to know. European Archives of Oto-Rhino-Laryngology 2009; 266(5):623-5

7. Toohill RJ, Lehman RH, Grossman TW, Belson TP. Rhinitis medicamentosa. The Laryngoscope 1981; 91(10):1614-21

8. Fleece L, Mizes JS, Jolly PA, Baldwin RL. Rhinitis medicamentosa. Conceptualization, incidence, and treatment. The Alabama journal of medical sciences 1984; 21(2):205

9. Ramey JT, Bailen E, Lockey RF. Rhinitis medicamentosa. Journal of Investigational Allergology and Clinical Immunology 2006; 16(3):148

10. Sharma R. Revised Kuppuswamy's socioeconomic status scale: Explained and updated. Indian pediatrics. 2017; 54(10):867-70

11. 11.Gill SN, Al Sallom JM, Adamu NS, Ferej RA, Alagheband $\mathrm{Z}$, Mustapha $\mathrm{H}$ et al. Assessment of the utilization pattern and related knowledge of nasal decongestants among university students in Ajman, UAE. Gulf Medical Journal 2015; 4(1):3644

12. Bennadi D. Self-medication: A current challenge. Journal of basic and clinical pharmacy 2013; 5(1):19

13. Lenz D, Cardoso KS, Bitti AC, Andrade TU. Evaluation of the use of topical nasal decongestants in university students from health sciences courses. Brazilian Journal of Pharmaceutical Sciences. 2011; 47(4):761-7

14. Zareen S, Zareen H, Ateeq M, Rehman HU, Mohammad W, Achakzai SS. Xylometazoline: A tropical Nasal Decongestant and an extensive cause of Rhinitis medicamentosa (RM). Bull. Env. Pharmacol. Life Sci. 2016; 6:28-32

15. Shah R, Ramanuj V, Bala DV. Evaluation of Self-medication among Urban Population of Paldi area, Ahmedabad. National Journal of Community Medicine. 2015;6(3):445-8.

16. Dewanjee D, Mitra A, Chatterjee J. Study of self medication of allopathic medicine among college students in West Bengal. In Systems in Medicine and Biology (ICSMB), 2010 International Conference on 2010 Dec 16 (pp. 446-9)

17. Aziz MM, Masood I, Yousaf M, Saleem H, Ye D, Fang Y. Pattern of medication selling and self-medication practices: A study from Punjab, Pakistan. PloS one 2018;13(3):e0194240

18. Bochenek T, Godman B, Lipowska K, Mikrut K, Zuziak S, PedziszM et al (2016) Over-the-counter medicine and dietary supplement consumption among academic youth in Poland. Expert Rev Pharmacoecon Outcomes Res. 2016; 16:199-205

19. Albsoul-Younes A, Wazaify M, Yousef AM, Tahaineh L. Abuse and misuse of prescription and nonprescription drugs sold in community pharmacies in Jordan. Substance Use \& Misuse 2010; 45(9):1319-29

20. Ahmad A, Patel I, Mohanta GP, Balkrishnan R. Evaluation of self medication practices in rural area of town Sahaswan at Northern India. Annals of Medical and Health Sciences Research 2014; 4(8):73-8. 